\title{
Remote Lab Activities in a Digital Age: Insights into Current Practices and Future Potentials
}

\author{
M. A. Gunasekara ${ }^{1}$ \\ Thathsara D. Maddumapatabandi ${ }^{2}$ \\ Kelum A. A. Gamage ${ }^{3}$
}

\begin{abstract}
Laboratories and practical workshops are a crucial element in science, technology, engineering, and mathematics (STEM) subject streams in higher education, where the COVID-19 pandemic has created an unprecedented challenge in conducting such activities face-to-face. Many universities in the western world are now experimenting with various platforms to conduct laboratory activities remotely, in conjunction with online delivery of teaching. It demands significant adjustment to traditional face-to-face laboratory activities, where this paper investigates the practices universities currently adapted and potential future technologies available for remote delivery of laboratories. This paper also identifies the areas for enhancement of students' remote laboratory experience, and a survey was also conducted to identify students' perception of laboratory activities during online and hybrid delivery of teaching. The research study explored current practices of remote lab delivery and also provide an insight into the future potentials of remote lab activities in a digital age.
\end{abstract}

Keywords: Remote laboratory, Virtual laboratory, Higher education, Online teaching, Technology.

\footnotetext{
1 Teaching Assistant, School of Engineering, Sri Lanka Technological Campus (SLTC), Meepe, Padukka, 10500, Sri Lanka. Email:malindag@sltc.ac.lk

2 Senior Lecturer, Sri Lanka Technological Campus (SLTC), School of Arts \& Sciences, Meepe, Padukka, 10500, Sri Lanka. Email: thathsaram@sltc.ac.lk

${ }^{3}$ Associate Professor, James Watt School of Engineering, University of Glasgow, Glasgow, G12 8QQ, UK. Email: kelum.gamage@glasgow.ac.uk
} 


\section{INTRODUCTION}

The COVID-19 pandemic, caused by severe acute respiratory syndrome coronavirus 2 (SARS-CoV-2), has become an unprecedented global catastrophe affecting people's lives and disrupting a variety of sectors. Governments of all the countries are taking their best preventive measures from simple physical distancing to lock-downs to flatten the COVID-19 infection rate, and to minimize the fatalities. The education sector has also been greatly impacted by the pandemic causing a worldwide shutdown of academic institutions including schools, colleges, and universities, to prevent large student-community gatherings which presents a potential threat of developing a sudden outbreak (Crawford et al., 2020).

Amidst the crisis, the majority of higher education institutions have been able to replace the physical mode of delivery with online platforms as the safest immediate solution. Online learning, computer-mediated learning, web-based learning, a few of which falls under the widespread virtual reality (VR) and distant education paradigm (Sarumi, 2020). It also conveys the idea that the availability of a device, capability to work using device and network connection or internet accessibility are required to accomplish distance education (Dhawan, 2020). Although shifting to an online platform is the safest preventive measure taken, inequities and inadequacies in education systems are still been argued (Kemp, 2020). Nevertheless, online education has become the new normal of education throughout the world.

Among numerous fields of education, Science, Technology, Engineering and Mathematics Education, which is widely known as STEM education, has become a major driving force behind the massive technological development in the world. The STEM education has been identified as essentially required in facilitating economical development, creation of jobs as well as international competitiveness (Uhomoibhi et al., 2014) where STEM would be beneficial in solving real-world problems through integrated, multidisciplinary, interconnected approaches as well as important in enhancing the critical thinking skills of the students (Hafni et al., 2020). Achieving hands-on experience through practical laboratory sessions is an important aspect of STEM education. There are a variety of objectives achieved through laboratory sessions such as teaching fundamental practical skills, to use equipment handling, educate students on taking observations and decisions, enhancing communication skills, linking the gap between the theoretical knowledge and experimental concepts to better achieve concurrent engagement of lectures and laboratory sessions etc.(Gibbs, G., \& Habeshaw, 2011; Rowe et al., 2018). Ultimately, the practical sessions strengthen the learning process and stimulate scientific attitudes (Dan-Ologe \& Shittu, 2012). Due to the COVID-19 pandemic situation, the majority of the university programs had to be delivered through online mode including laboratory sessions. Delivering physical laboratory sessions through online mode is indeed a challenge and holds a huge responsibility. STEMbased laboratories have to provide actual hands-on experience as well as effective skill acquisition, which could be fulfilled either through remote access to real labs or virtual laboratory sessions (Potkonjak et al., 2016). 


\section{METHODOLOGY}

This article used the method of systematic literature review, which presents the current practices and the future potentials of conducting remote lab experiments. The first goal was to understand how peer-reviewed literature demonstrates the methods of face-to-face learning and the transition into remote learning. The scope of the search limited to key-words such as remote lab experiments, virtual lab, COVID-19, higher education, distant learning, challenges, and future potentials. This article summarizes the laboratory activities through remote learning technologies, laboratory activities through virtual laboratory platforms and techniques and laboratory activities through AR as a part of the literature review findings.

We then presented an analysis of student perspective based on data we have collected a survey among first-year undergraduates at Sri Lanka Technological Campus (SLTC), Sri Lanka. There were 34 short answer type questions for them to directly choose their opinion and couple of questions included to explain their own thoughts in the survey questionnaire. Questions for the questionnaire survey were prepared based on the experience obtained through labs conducted online.

Students were from Biosystems Engineering (a group of 30 students), Information Technology (a group of 33 students) and Agricultural Technology students (a group of 37 students). The key aim of the study was to explore the student perception and effectiveness in delivering labs and to foresee the potential direction of future laboratory education.

The laboratory portion of each course module is synchronized with in-class lectures, allowing students to gain a better understanding of the theories and concepts that they learn. Lecture notes and all necessary materials for laboratory component were distributed through the Learning Management System (LMS), and the lecture delivery and discussions were conducted through ZOOM. In addition, recorded videos/YouTube links were shared relevant to each experiment as demonstrations. Pre-lab questions helped in guiding the labs and to direct students to the experiments. Students were asked to write a laboratory report for each laboratory session as usual, including all the components as they used to do. Data sets were given when calculations and analysis were required to perform.

\section{REVIEW OF LITERATURE}

\subsection{Overview}

Various opinions on the delivery of online labs have been identified. An article by Loike, J. D., \& Stoltz-Loike,(2020) suggests that undergraduate level science-based labs can be successfully taught online, promoting an active learning experience, but modifications are required. Due to reduced human resources and spatial requirements, online laboratory sessions are also economical than running physical laboratory sessions (Aziz et al., 2009). As suggested by Loike, J. D., \& Stoltz-Loike, (2020) activities such as reviewing literature and peer-reviewed journals, designing advanced experiments and analyzing data are a few of the key activities which needs to be included in delivering online-based science laboratory sessions.

Numerous techniques are being used to deliver STEM laboratory sessions effectively through distance learning, where virtual platforms and simulations are widely used. According to Chen et al., (2010) virtual labs and remote labs are the two approaches the online labs could 
be conducted. Two types of online labs available, one of which is virtual labs which are conducted through software such as Matlab/Simulink, Java Applet, LabVIEW (Chen et al., 2010). In addition, various universities in the western world have identified, proposed, applied various platforms and techniques to conduct laboratory activities remotely. These are suggested to be pursued in conjunction with online delivery of teaching, and further experimenting. Apart from the obvious benefits, these novel techniques and applications are undoubtedly important in enhancing technological literacy in terms of utilizing technological devices in education.

Laboratory sessions develop a variety of skills in the students, where online lab sessions can also use to develop those skills. For instance, collaborative learning is an important aspect in engineering education. According to Gravier et al., (2012) an innovative system has been developed to promote collaborative learning in engineering education, where users get notified of their actions in the platform and interaction with the others.

Augmented Reality (AR) is another emerging technology in the field of education (Andújar et al., 2011; Mejías Borrero \& Andújar Márquez, 2012). Though AR labs are not yet widely used, they would significantly contribute in the near future. Along with overcoming technological challenges, AR labs will eventually benefit the future of education due to reasons such as their positive impact on learning, while reducing extraneous cognitive processing (Thees et al., 2020). The application of augmented reality in education is still at an initial stage (Khan et al., 2019). One of the studies conducted to investigate the effects of AR technology in developing skills in science laboratories have obtained both negative and positive comments (Akçayır, M., Akçayır, G., Pektaş, H. M., \& Ocak, 2016). The usefulness of AR technology in improving the laboratory skills of the students have also been recognized in the same study (Akçayır, M., Akçayır, G., Pektaş, H. M., \& Ocak, 2016). Based on another pilot study conducted on a developed augmented reality-based lab system had conveyed that further possibilities can be addressed in AR labs on online mode than traditional labs (Borrero et al., 2013). Also, based on the results obtained from another comparative study on AR labs, virtual labs, and hands-on physical labs, students show positive feedback on AR labs, where they have identified them to be beneficial in terms of user-friendliness, and flexibility (Cuendet et al., 2013).

Thus, there are a variety of current practices reported and are emerging in the field of distance education. Adapting to remote learning has many hurdles and one of the largest is engaging scientific inquiry from a distance to give hands-on training while satisfying learning outcomes and objectives. This review would give a deeper insight into those remote laboratory experiences and future potentials of the development of online laboratory sessions in STEM education, enhancing the quality of education.

\subsection{Laboratory Activities Through Remote Learning Technologies}

This section provides details and the experience obtained delivering general chemistry laboratory course through remote teaching. Laboratory component in general chemistry is considered as a difficult area to be delivered through remote learning due to several reasons. This study has provided various aspects in delivering the course through remote learning along with suggested future improvements. 
Due to the emergence of the COVID-19 pandemic situation laboratory sessions had to be shifted into online mode. In the online mode, premade instructional videos have been utilized in replacing in-person pre-laboratory lectures based on prior feedback. Instructional videos designed to promote self-paced learning, including embedded quiz questions, and utilizing interesting teaching strategies have undoubtedly identified as beneficial for the students. Interactive laboratory videos had also been utilized allowing the students to engage in the experiment on the experimenter's shoes along with facilitating all possible ways aiding to visualize the experiment. Another strategy that had been used was the incorporation of hybrid laboratory reports where reasoning for experimental protocols had been included, allowing the students to enhance intuition and critical thinking (Wang \& Ren, 2020). Initially, the transition to remote learning had been difficult for the students. Having said that, according to the feedback from students, interactive laboratory videos, as well as the questions in the hybrid laboratory reports, had been helpful to overcome the difficulties. Based on the feedback taken at the end of the course, conducted through remote learning, the majority of students had agreed or strongly agreed, that they enjoyed the overall lab experience and expressed that they learnt a lot as well. Based on the student suggestions, the degree of difficulty in the questions to be addressed in the hybrid reports, and the lengthy reports had been identified as the aspects which needs to be improved (Wang \& Ren, 2020).

Overall, the study expresses that more improvements need to be done for remote learning delivery procedure. One of the future key improvements identified as, holding teaching assistant guided discussion sessions through virtual labs for each group comprising of about sixteen students. After that sub grouping students to further discuss the initial part of the hybrid laboratory report lab activities fostering the interaction had also been proposed to be carried out as one of the improvements in the plan (Wang \& Ren, 2020).

Further utilizing computer modeling software has also been suggested as a future key improvement. Conducting hybrid laboratory sessions allowing students to perform experiments had also been suggested as a future improvement. Laboratory activities alleviating loneliness and promoting peer collaboration had also been suggested. Also updating the existing video repository with newer videos and introducing inquiry-based virtual experiments had also been identified as useful in the future improvement process. In summary, though physical laboratory sessions cannot be replaced through remote learning, various types of strategies and techniques can be used to enhance students remote learning process during pandemic situations such as the COVID-19 situation (Wang \& Ren, 2020).

Another research study had focused on how short case-based learning is utilized in delivering remote-teaching online laboratory for biochemistry labs. The short case-based learning technique had been applied for online biochemistry labs exhibiting numerous benefits such as enhancing the student perception and achievement, aiding the retention of information etc. This case-based learning approach application, contains four major steps including, "Plan, Organize, Implement and Evaluate". In the planning step, the objective of the particular application had been designed utilizing Bloom's taxonomy. In the organizing step the students had been grouped, and the expectations had been explained. In the implement step, questions had been provided to each group. In the final step, more challenging questions had been provided to further assess students' understanding and evaluation purposes as well. 
Though the application had been identified as challenging at the beginning, with experience it had become much easier. Further they have identified that ten questions for a particular case study, and five students per group as the most feasible arrangement to be implemented. The questions had been designed to move from simple to complex based on real-world scenarios. The study based on case-based learning had shown successful results in various aspects, proving its potency (Thibaut \& Schroeder, 2020).

\subsection{Laboratory Activities Through Virtual Laboratory Platforms and Techniques}

Virtual laboratories are one of the most common methods of delivering laboratory experiments in online education. The experiment discussed herewith, summarizes a research project which was conducted to investigate the effectiveness of virtual laboratories for delivering a biology course for undergraduate level students. The study had conducted with the participation of 19 students, where the students had to design an experiment using computer simulations in virtual laboratories. After obtaining the experimental data, the understanding of materials had been assessed through laboratory-specific questions. Also, students had been directed to participate in traditional laboratory sessions as well. The students' perception of the study had been obtained at the end of the semester, after conducting overall ten cognate virtual and traditional labs, five laboratories for each. As shown in Figure 1, more than half of the participants have either agreed or strongly agreed that they think they have learned more biology concepts participating in virtual labs compared to traditional labs (Flowers, 2011).

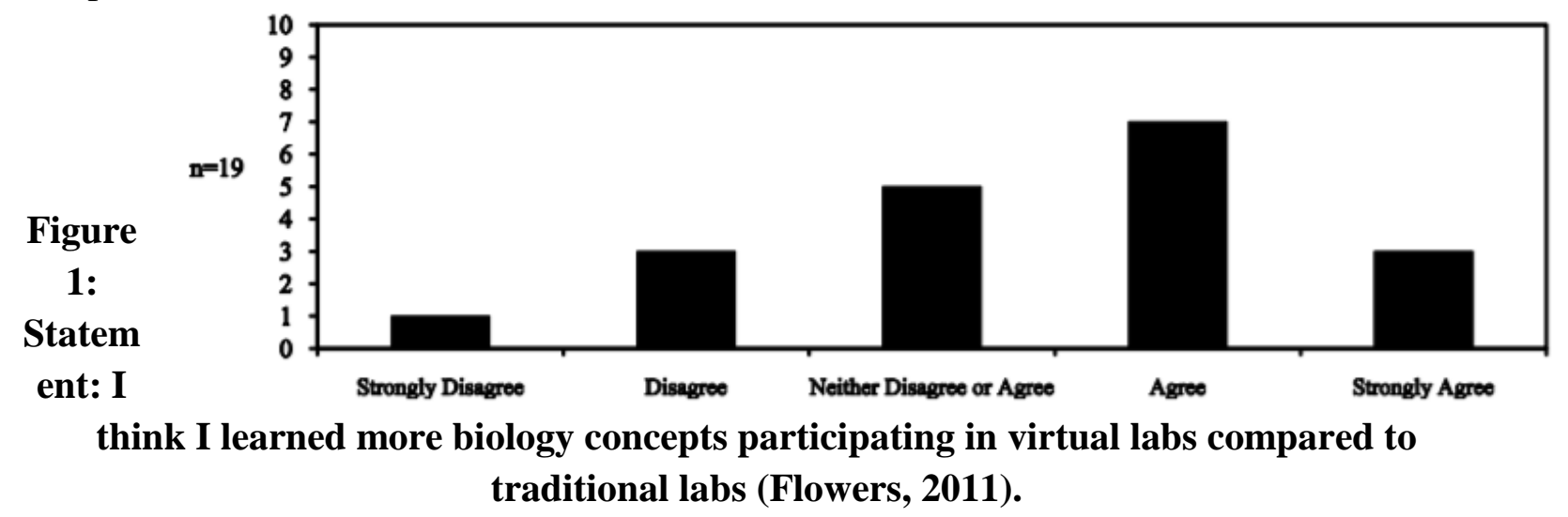

Further, the study shows below $26.32 \%$ of the students have strongly agreed whereas 21.05 $\%$ agreed cumulatively, exceeding the $\%$ disagreement, on that they have learned more on performing biology laboratory techniques in virtual laboratories compared to traditional laboratories.

Hands-on experience is difficult to replace using virtual labs. The fact that the experience in handling equipment cannot be easily replaced through virtual labs, had been proved in the study as the majority of the students have disagreed that they have learned more on equipment through virtual labs compared to traditional laboratory sessions.

As the below Figure 2 expresses, cumulatively over half of the students preferred participating in virtual labs compared to traditional labs as well. 


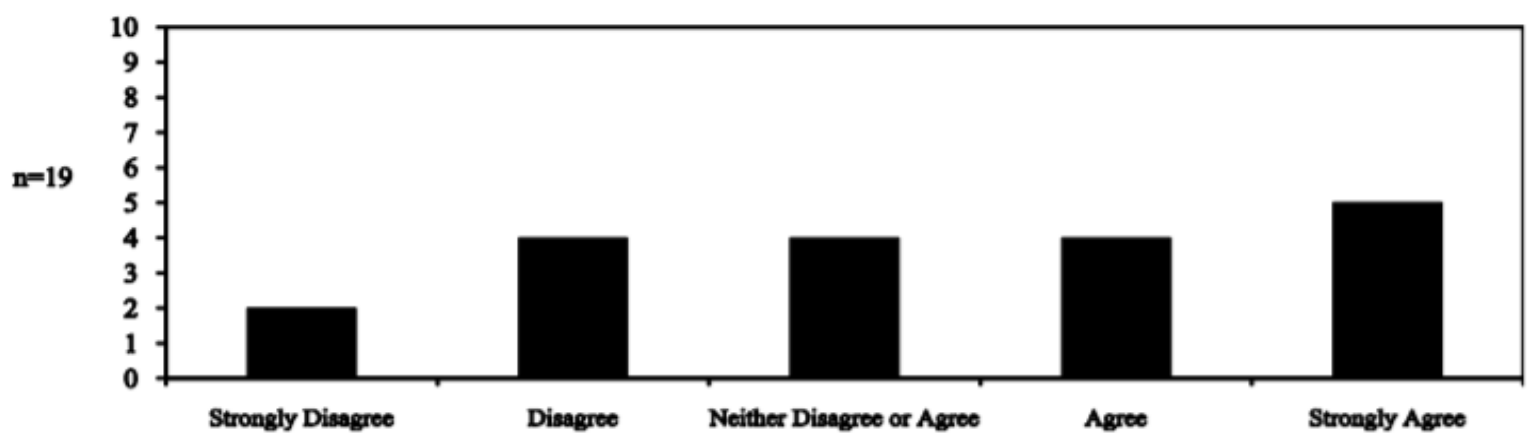

Figure 2: Statement: I think I learned more about how to perform biology laboratory procedures in virtual labs compared to traditional labs (Flowers, 2011).

Knowing the fact that the majority of student's prefer virtual labs over traditional labs suggests that the future of online laboratory delivery is promising (Flowers, 2011).

A study had been investigated hands-on experience and virtual laboratory experience for natural science and physics. Physics being innately an experimental science, laboratory component in physics education is considered as integral for undergraduate (American Association of Physics Teachers, 2014). According to their study, knowledge construction, modelling, experiment designing, development of technical and practical skills, data analyzation and visualization and proper communication are the major areas to be focused on in achieving learning outcomes in physics education. In summary, undergraduate level physics laboratory is an integral part of the undergraduate level. Thus, the effectiveness of delivering hands-on labs as virtual labs is assessed in another study conducted by Darrah and co-workers. Their study had evaluated the hands-on laboratory experience and virtual laboratory experience through comparison, by utilizing 224 students from Auburn and Penn State Universities.

The virtual lab utilized in the study consisted of four main stages. Input had been provided to the design by physics experts in the first stage, whereas lab development had been carried out in the second stage by engagement of experts and designers of software and the lessons. In the third stage user interface, pedagogical approach and the content had been evaluated by another group of experts in physics. In the final stage, the labs had been reviewed by the students who enrolled in introductory college-level physics. Also, those group of students had used in assessing student learning as well. The Virtual Physics Lab ${ }^{\mathrm{TM}}$ software used comes with the Five E cycle, which consist of laboratories having content, integration of technology and formative assessment planned sequentially (Darrah et al., 2014).

Each laboratory consisting of the basic information, concepts and objectives, pre-laboratory questions, equipment list, demonstration videos, post laboratory questions and a quiz, where virtual laboratory experiment containing real-time 3D simulations through simulated equipment featured as the primary component. The study had concluded that these virtual laboratories posse various advantages. One of the advantages featured is that their availability for the students who could not participate in the laboratory session. The study had shown that neither virtual labs nor physical labs had been identified as more effective in terms of delivering the concepts of the experiment for the students. Also, the study had suggested that 
some of the hands-on laboratories can be effectively replaced by virtual labs. In conclusion, based on the findings of the study conveys that both universities that participated in the study had shown that the virtual labs were as effective as traditional physics labs which were carried out providing hands-on experience.

Another study had been carried out exploring the efficacy of virtual laboratory sessions through the students' perception who were engaged in a one-month intensive laboratory training course. Along with being the first virtual laboratory experience for the students, a survey questionnaire had been used to identify the student perception regarding the traditional and virtual laboratory sessions. A system containing simulated experiments had been used by the students in the study. The project had allowed the students to perform virtual experiments remotely at any convenient time using either via a remote machine through the internet or a local machine.

Then a questionnaire containing both open-ended and close-ended questions covering various aspects from general demographic questions to students' perception and students' usage of laboratories had been inquired and surveyed using fifty engineering students. Based on the survey results and comments, the research findings have shown the addition of virtual laboratories outside traditional laboratory hours have enhanced student learning. As shown in Figure 3 the study further expresses that $48 \%$ of respondents had strongly agreed or agreed to statement that the virtual labs are more suitable to senior students than first-year students. 


\begin{tabular}{|c|c|c|c|c|c|c|}
\hline \multirow{2}{*}{$\begin{array}{l}\text { Survey Items } \\
\text { I found the traditional laboratory workshop: }\end{array}$} & \multirow[b]{2}{*}{$\begin{array}{c}\text { Sample } \\
\text { (n) }\end{array}$} & \multicolumn{5}{|c|}{$\%$} \\
\hline & & SA & A & $\mathbf{N}$ & D & SD \\
\hline Easy to operate & 47 & 8.5 & 49 & 34 & 8.5 & 0 \\
\hline Easy to understand & 50 & 8 & 48 & 36 & 8 & 0 \\
\hline Flexible to use in relation to time and place & 50 & 6 & 46 & 34 & 8 & 6 \\
\hline Stimulating & 50 & 12 & 38 & 42 & 6 & 2 \\
\hline Satisfying & 50 & 12 & 40 & 40 & 8 & 0 \\
\hline I found the virtual laboratory workshop: & $\underset{\text { Sample }}{\text { Sample }}$ & SA & A & $\mathbf{N}$ & D & SD \\
\hline Easy to operate & 49 & 12 & 45 & 37 & 4 & 2 \\
\hline Easy to understand & 50 & 10 & 42 & 38 & 6 & 4 \\
\hline Flexible to use in relation to time and place & 50 & 10 & 40 & 40 & 8 & 2 \\
\hline Stimulating & 50 & 8 & 44 & 38 & 6 & 4 \\
\hline Satisfying & 50 & 6 & 42 & 42 & 6 & 4 \\
\hline Survey Items & $\begin{array}{c}\text { Sample } \\
\text { (n) }\end{array}$ & \multicolumn{2}{|c|}{$\begin{array}{c}\text { Strongly } \\
\text { agreed/Agreed } \\
\%\end{array}$} & Neutral \% & \multicolumn{2}{|c|}{$\begin{array}{c}\text { Strongly } \\
\text { disagreed/ } \\
\text { Disagreed \% }\end{array}$} \\
\hline $\begin{array}{l}\text { I think Virtual Lab Workshop is more suitable } \\
\text { for senior students (2nd year students and } \\
\text { above) }\end{array}$ & 50 & \multicolumn{2}{|c|}{48} & 48 & \multicolumn{2}{|c|}{4} \\
\hline $\begin{array}{l}\text { I think that I learn and understand more in a } \\
\text { virtual lab environment than a traditional lab }\end{array}$ & 50 & \multicolumn{2}{|c|}{40} & 46 & \multicolumn{2}{|c|}{14} \\
\hline \multirow{2}{*}{$\begin{array}{l}\text { If I can use virtual laboratory workshop over } \\
\text { the Internet instead of physically staying in } \\
\text { a laboratory, I (will/will not use) }{ }^{\star} \text { the virtual } \\
\text { laboratory workshop outside lab hours for } \\
\text { distance learning. }\end{array}$} & \multirow[b]{2}{*}{42} & \multicolumn{3}{|c|}{ Will } & \multicolumn{2}{|c|}{ Will not } \\
\hline & & \multicolumn{3}{|c|}{81} & \multicolumn{2}{|c|}{19} \\
\hline
\end{tabular}

Figure 3: Percentages of students' degree of agreement or disagreement (Chan \& Fok, 2009).

Furthermore, $81 \%$ of the students who had accepted, for distance learning, will use virtual lab workshops outside lab hours, if they can use the workshop virtually instead of physically engaging in a laboratory.

One of the students who participated in the study had mentioned that he did not participate in the traditional EEE labs, as traditional labs are not required and appropriate for a computer scientist. According to the obtained comments, another student had been identified who was not even aware of the processes that occur in virtual lab sessions. Conversely, some of the participated students had commented that virtual labs can be used to familiarize theories, and that both practical and virtual labs are useful. Some students had mentioned that practical labs need to be conducted as the basic principles are learnt through them. In addition, another student had mentioned that both the virtual lab sessions and the physical lab sessions are important as well. Though replacing the traditional labs with virtual labs is not a feasible solution, the study suggests that enhanced study can be facilitated through virtual labs. The 
study has expressed pedagogical advantages and disadvantages of virtual labs as follows shown in Table 1.

\section{Table 1: Projected pedagogical advantages and disadvantages of virtual laboratories} (Chan \& Fok, 2009)

\begin{tabular}{|c|c|}
\hline Advantages of virtual laboratories & Disadvantages of virtual laboratories \\
\hline $\begin{array}{l}\text { Enables laboratory experience at any time and } \\
\text { anywhere }\end{array}$ & $\begin{array}{l}\text { Discourages students from learning the physical } \\
\text { instruments and real devices }\end{array}$ \\
\hline $\begin{array}{l}\text { Allows students more opportunities to practice } \\
\text { experiments, particularly for those that may not be } \\
\text { easily replicated due to resources, time and safety } \\
\text { issues }\end{array}$ & $\begin{array}{l}\text { Remote access discourages direct collaboration and } \\
\text { interaction amongst students and teachers }\end{array}$ \\
\hline $\begin{array}{l}\text { Provides a safe workshop environment without the } \\
\text { need for supervision }\end{array}$ & Increased risk of plagiarism in assessment \\
\hline $\begin{array}{l}\text { Enhances students' enthusiasm for learning through } \\
\text { interactivity }\end{array}$ & $\begin{array}{l}\text { Physical, practical skills that are expected of an } \\
\text { engineer are not honed }\end{array}$ \\
\hline \multicolumn{2}{|l|}{ Increase students' IT literacy } \\
\hline \multicolumn{2}{|l|}{$\begin{array}{l}\text { Many industries are using simulation software for } \\
\text { testing and development and students are getting a } \\
\text { flavour of this }\end{array}$} \\
\hline \multicolumn{2}{|l|}{$\begin{array}{l}\text { Contact laboratory hours are scarce. Students can use } \\
\text { virtual laboratories to reinforce the theoretical concepts } \\
\text { they learn in class }\end{array}$} \\
\hline \multicolumn{2}{|l|}{$\begin{array}{l}\text { More cost-effective, particularly for complicated circuits } \\
\text { that may require a number of trials and errors }\end{array}$} \\
\hline \multicolumn{2}{|l|}{ Can provide attendance and other student information } \\
\hline $\begin{array}{l}\text { Online feedback and assessment can be made readily } \\
\text { available }\end{array}$ & \\
\hline
\end{tabular}

Further, the study suggests that various challenging demands on the field of engineering education can be mitigated through virtual laboratories. Also, the study confirms the importance and the need for further research on online learning to improve delivery and student learning process.

Another research study discussed here evaluates the virtual laboratory sessions in the field of mechanical engineering. Both faculty members and students of mechanical engineering branches of different educational institutes had been a part of the project. The session had been carried out for the faculty as a faculty development programme (FDA) throughout a period of one week. The faculty FDA training sessions had consisted of taking measurements, remotely triggered VLA's and simulations on fields such as fluid mechanics, metallurgy and materials engineering, machine kinematics. Feedback had been given on the final session day and analyzed. The students had performed the experiment through virtual laboratory sessions for fluid mechanics through VLAB2020 system. Then videos on real laboratory experiments had also been shared for the comparison of virtual and real experimental results. Finally, a questionnaire had been provided to the students to obtain feedback (Kapilan et al., 2021).

The majority of the faculty members had denoted that they have improved in terms of knowledge and skills. As it can be seen from Figure 4, based on the analyzed data, $96 \%$ of the students had been happy about the performed virtual laboratory experiments, whereas 89 $\%$ had mentioned that virtual labs aided in self-learning as well. 


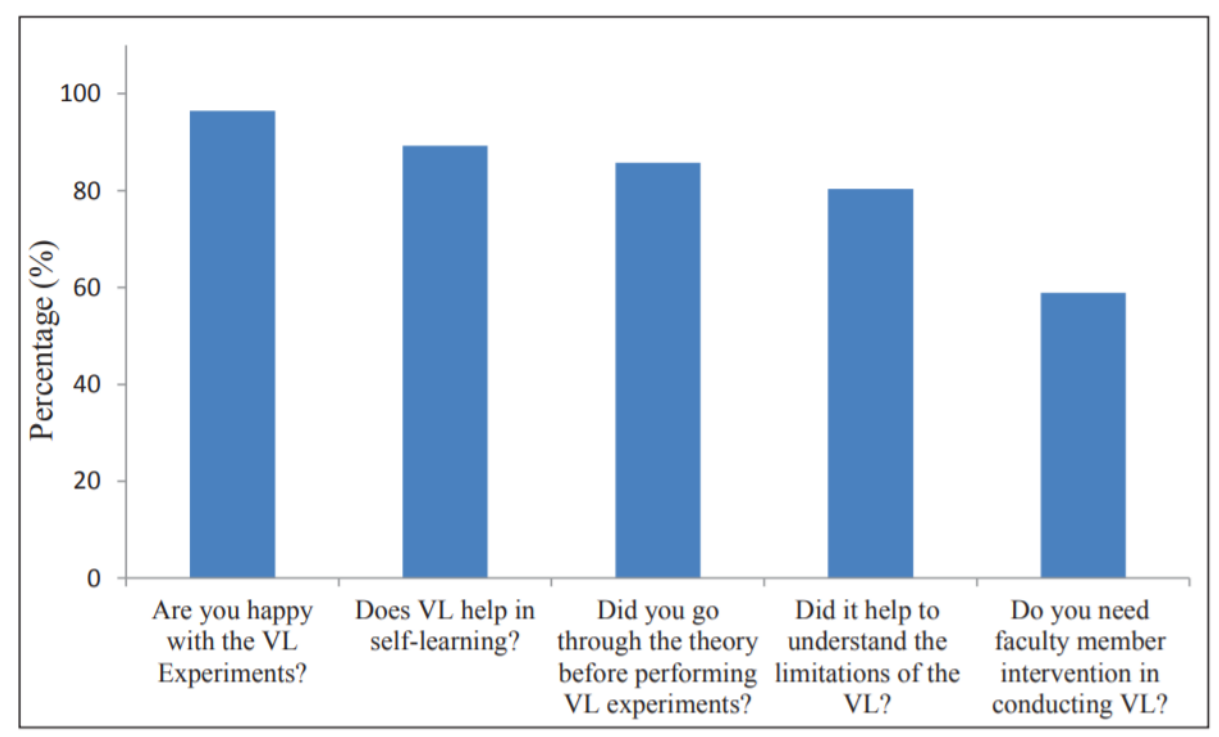

Figure 4: Students' feedback part 01 regarding the Fluid mechanics Virtual Labs

(Kapilan et al., 2021)

As it can be seen in the above Figure 4 the majority of students $(86 \%)$ had gone through the theory parts before conducting the virtual experiments. As linking the theoretical knowledge with the practical experiments are extremely important, students' prior preparation could have been a positive effect on the students' learning process as well.

Further, as the study shows the students are comfortable in participating in the virtual labs, where a few students had mentioned that they had network connectivity issues in participating the virtual labs. Moreover, as Figure 5 shows more than half of the students had selected that quality of learning increases from the virtual labs and virtual labs needs to be introduced into the curriculum also (Kapilan et al., 2021).

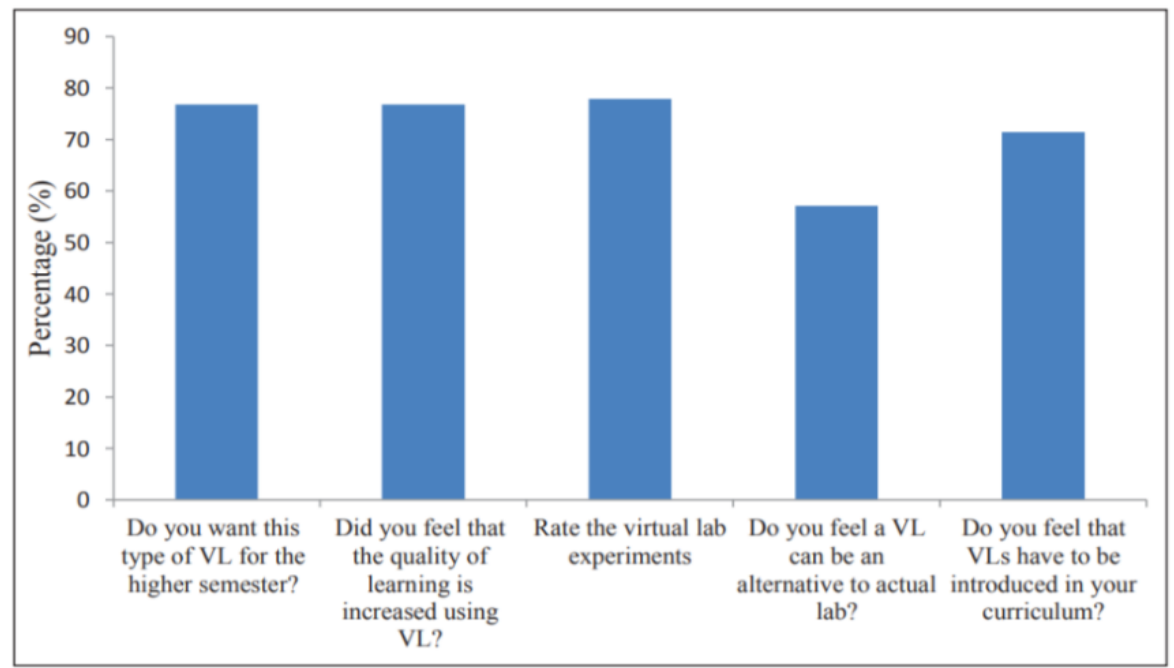

Figure 5: Students' feedback part 02 regarding the Fluid Mechanics Virtual Labs (Kapilan et al., 2021). 
According to Figure 5, the majority (77\%) of students had selected that they require virtual labs for the higher semesters also. A considerable number of students (57\%) had expressed that virtual labs could be the alternative for the delivery of the laboratory sessions during the SARS-CoV-2 pandemic situation as well. Overall, the feedback had conveyed positivity towards the virtual labs among both the students as well as the faculty members. The study has shown that the virtual labs had been able to enhance the understandability conjointly enhancing the student learning process as well.

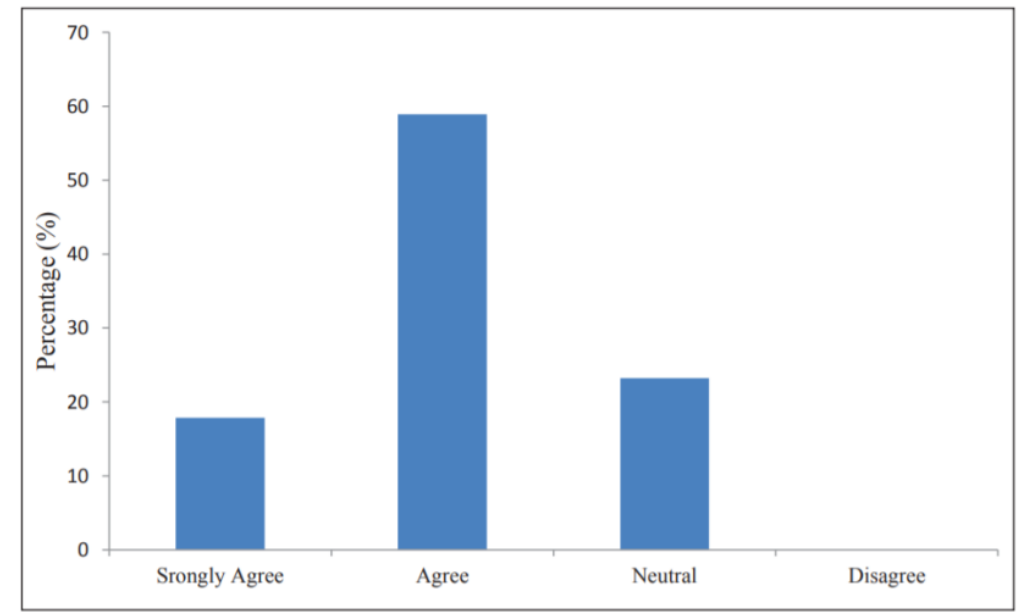

\section{Figure 6: Student feedback regarding the learnability of the VL Experiments (Kapilan} et al., 2021).

The above Figure 6 shows student opinion regarding learnability of the VL Experiments, which had been asked through the question whether it had been easy to learn and perform the virtual experiments. As the results show $18 \%$ had strongly agreed whereas $59 \%$ had agreed to the query. Though $23 \%$ of students had been in neutral opinion, none of the students had disagreed. As the study suggests the students had been happy with the VL as it helps in learning, and it is also student centric. Also, the VL can be comfortably performed by the students on their own time as well. Internet connectivity issues, the absence of an interactive learning environment, lack of the required devices to carry out the experiments are a few issues identified in the study. Though a few issues exist, the overall impression and importance towards the virtual labs had been identified through the study (Kapilan et al., 2021).

The research study discussed below is also utilize virtual equipment and laboratories, in science and engineering education. This research study had implemented e-learning platforms and virtual laboratories for the second and fourth academic years at universities in several countries including the United States of America, United Kingdom and Russia, focusing on subjects such as bio manufacturing, chemistry and material sciences. In terms of laboratory education, laboratory assignments and virtual equipment had been used for authentic online experiments, prior preparation for actual labs and to assess the capability of practical problem solving and actual equipment handling as well. Based on research findings and meeting the 
student requirements, the virtual laboratories and e-learning activities had been developed through a platform named ATeL - Advanced Tools for e-Learning.

The core of the virtual labs had been based on highly interactive simulations whereas, designing real learning scenarios had been reproduced through solid science or mathematical models integrated environments. To achieve the particular learning outcomes, customized virtual experiments which were self-directed had also been introduced into the systems. Simulations and techniques enhancing students learning process achieving learning objectives was a major aspect in those systems as well. Based on the feedback of the students, it had been identified these lab sessions have been aided in the visualization of processes. The study shows that the practical assignments which were impeded due to various reasons could also be performed through e-learning tools. Various virtual labs have also been effective in terms of time-saving, enhancing student confidence, and bridging the gap between practical experiments and theoretical knowledge (Cherner et al., 2020).

\subsection{Laboratory Activities Through Augmented Reality}

Though laboratory sessions being an integral part of engineering education, performing practical experiments due to limited time available for the equipment usage among a large number of students has become a ceaseless problem. Although this issue had been addressed with regards to engineering education in the study, it can be widely observed among other fields as well. The study had focused on providing more effective experience augmenting virtual objects creating a real laboratory experience. To utilize the augmented reality technique more effectively to enhance the experimental performance, an innovative system had been used in the research study. After the development of the Augmented Reality (AR) lab model, comparison had been done along with equivalent conventional and virtual laboratories. A survey questionnaire had been used to obtain feedback where the developed AR lab had been well accepted according to the students. Below Table 2 shows the evaluation criteria results obtained based on the comparison of the traditional labs, virtual labs and augmented reality labs.

Table 2: Comparison of Hands-on labs, virtual labs and Augmented Reality labs (Odeh et al., 2012).

\begin{tabular}{|c|l|l|l|l|}
\hline$\#$ & Survey item & $\begin{array}{l}\text { Hand- } \\
\text { on lab }\end{array}$ & $\begin{array}{l}\text { Virtual } \\
\text { lab }\end{array}$ & $\begin{array}{l}\text { AR } \\
\text { lab }\end{array}$ \\
\hline 1 & Easy to use & $72 \%$ & $68 \%$ & $86 \%$ \\
\hline 2 & $\begin{array}{l}\text { Easy to understand the concept } \\
\text { theory }\end{array}$ & $80 \%$ & $76 \%$ & $78 \%$ \\
\hline 3 & Available for enough time & $44 \%$ & $82 \%$ & $84 \%$ \\
\hline 4 & Satisfying the knowledge theory & $80 \%$ & $68 \%$ & $80 \%$ \\
\hline 5 & Safe environmental for student. & $52 \%$ & $90 \%$ & $90 \%$ \\
\hline 6 & Progress new skills & $76 \%$ & $74 \%$ & $80 \%$ \\
\hline 7 & Teamwork's lab. is encouraged & $76 \%$ & $50 \%$ & $56 \%$ \\
\hline 8 & Comfortable physical place & $66 \%$ & $82 \%$ & $86 \%$ \\
\hline
\end{tabular}


As it can be seen in Table 2, the AR laboratory compared with its hands-on labs and virtual lab equivalences, had been identified as superior regarding the easiness of its usage. The same type of behaviour had been identified in physical spatial arrangement, the progress of novel skills and availability of time as well. Overall, the developed AR lab, through overlaying live video streaming with the application of subsidiary virtual objects had been a successful approach in engineering education.

\section{RESULTS}

This creation and implementation of the online environment to conduct laboratories is a new initiative in Sri Lankan universities due to the sudden transition as a result of the COVID-19 pandemic. Hence, a survey study was carried out at the Sri Lanka Technological Campus (SLTC) to better understand students' perspective of this new normal remote laboratory education. Our survey study constitutes the first step in determining the effectiveness of these online laboratory resources in aiding the preparation of students for the laboratories.

Overall, the survey participants thought that remote laboratory sessions are the best option available considering the unforeseen pandemic. In response to the question "Considering the current pandemic situation, online laboratory sessions are the best option available to conduct the labs." More than 50\% either agreed or strongly agreed in all degree programs (BSc Hons in BioSystems Engineering, B. Tech Hons in Agricultural Technology and BSc Hons in Information Technology in Software Engineering) as shown in Figure 7.

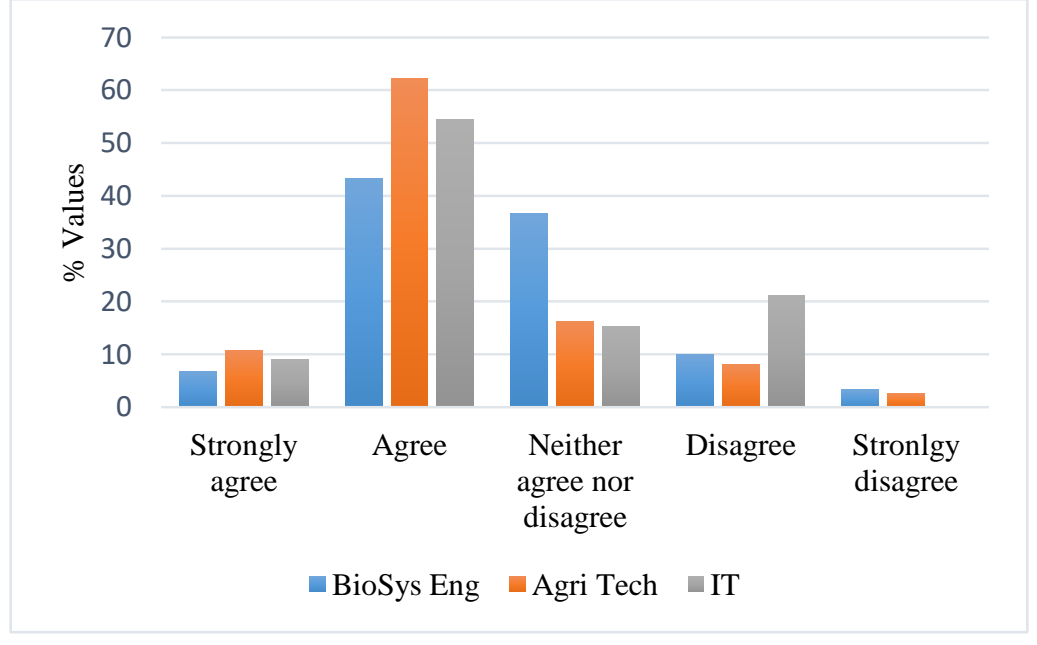

Figure 7: Student response to the survey question "Considering the current pandemic situation, online laboratory sessions are the best option available to conduct the labs"

According to the survey results shown in Figure 8, above $~ 50 \%$ of students were comfortable and pleased to know that they are coping up with remote learning tools such as LMS and Zoom. Proper guidance and assistance need to be provided for the small percentage of students who require additional support. 


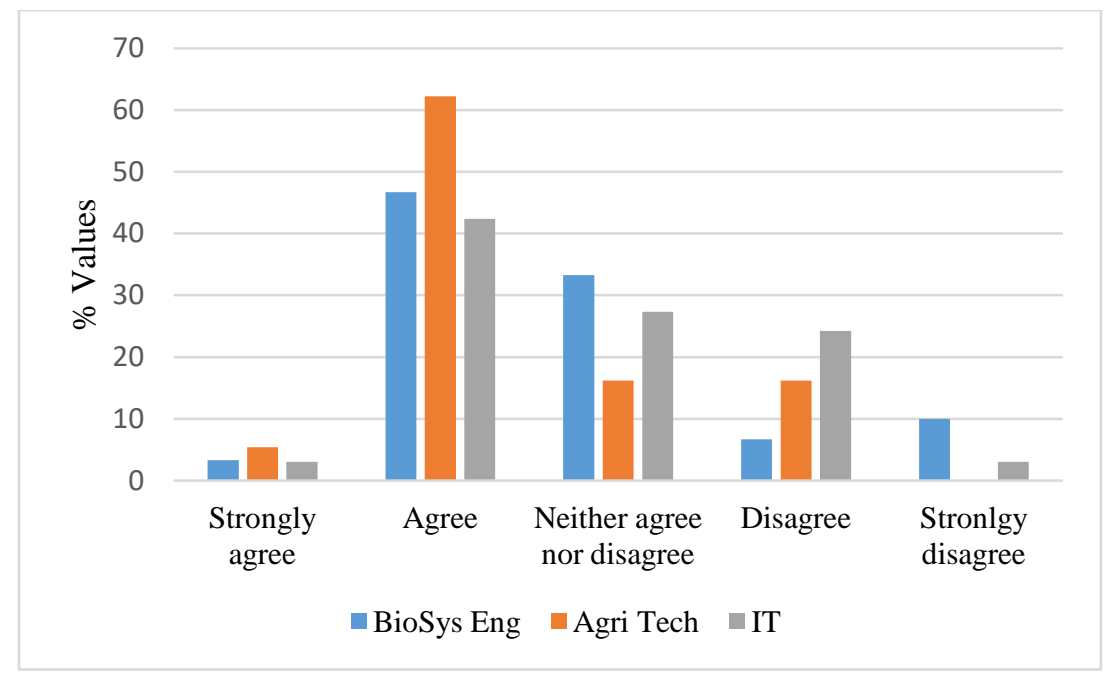

Figure 8: Student response to the survey question "How comfortable and easy to use remote learning tools"

Due to the self-isolation protocols of COVID-19, students learning environment could be disrupted in many ways and it is clearly depicted in survey data acquired in Figure 9.

Only less than $10 \%$ appear to have a very peaceful studying environment while the environment is not peaceful at all for $6 \%$.

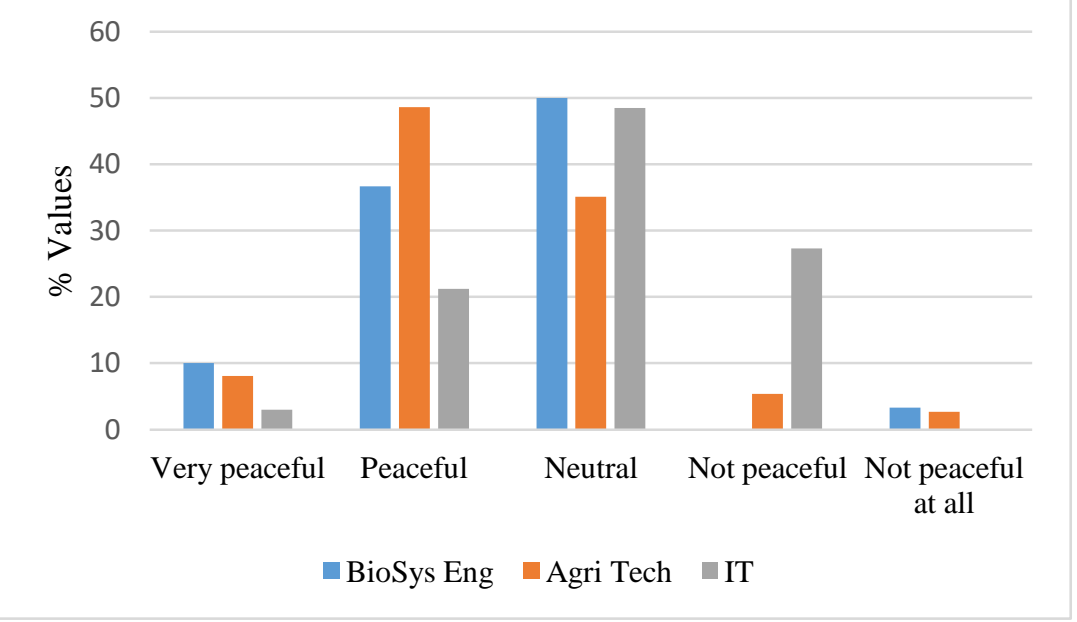

Figure 9: Student response to the survey question "How comfortable and easy to use remote learning tools"

Students much appreciated that they were able to acquire knowledge while staying at home and adopting to learn from home environment and therefore, students considered as a fruitful utilization of time during the pandemic. However, students strongly believe (BioSys 50\%, AgriTech $32.4 \%$ and IT $24.2 \%$ ) that the physical laboratories as an essential component as shown in Figure 10. Even the IT degree students believed that conducting laboratories are an essential component although most of their activities and tasks based on computer-based online labs. 


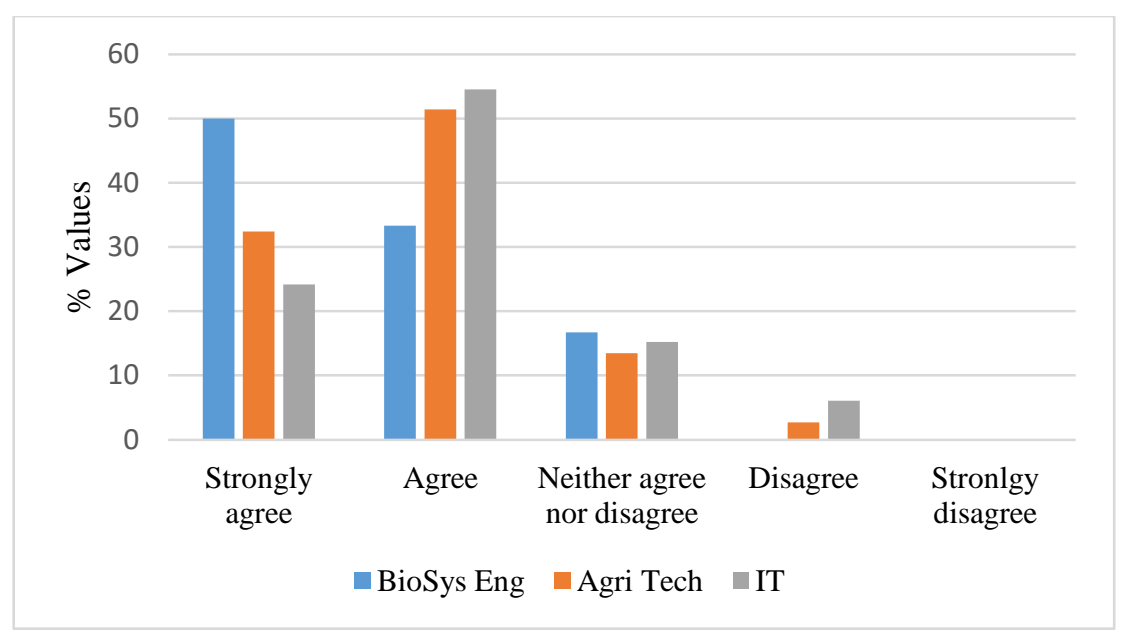

\section{Figure 10: Student response to the survey question about "learning new things even while at home"}

\section{DISCUSSION}

The concept of the remote lab is not very new to the world. It has been a practice in technical education especially when the student number is uncontrollable size (Christian et al., 1999). However, universities throughout the world had to take a sudden move to remote teaching and assessment since mid-March 2020 with no on-campus activities permitted according to COVID-19 preventive control measures imposed by the WHO.

Based on the analysis of survey questionnaire data, students were not very much satisfied with interaction through ZOOM during online laboratory sessions. Therefore, attention is much needed to use the virtual platform more interactively. For instance, the incorporation of more discussions and interactive sessions through breakout rooms to work as groups on a few tasks may help.

Students have communicated with the lecturer typically weekly and or whenever they needed assistance. Furthermore, students were satisfied and reasonably happy about the availability and accessibility of the lecturer. Students believe that they could stay focused long enough to complete their lab assignments at home. However, students may start to feel isolated due to the lack of active engagement in the virtual environment. This may cause some of them to disengage during the online sessions leading to limited understanding when it becomes difficult to ask questions and clarify on a real-time and ongoing basis.

In reference to the question regarding self-studying, the responses varied widely. This could be partly because these selected groups were fresh first-year students. Hence students are not much familiar with studying on their own referring to additional resources. Similarly, there can be students who do not enjoy self-studying due to their own reasons and nature and they may prefer to work as study groups.

A peaceful learning environment is one of the critical requirements accompanied by learning tools and resources (Gamage, 2020). Apart from the physiological surrounding, student satisfaction with necessary digital resources (laptop, mobile phone etc) to fully engage during remote lab sessions is crucial with stable network connections. And these requirements are not up to the satisfactory level in many areas where students come from. None of the students 
who took part in our survey satisfied with the stability and reliability of the internet connection to fully engage during remote lab sessions further supporting to the studies reported in literature (Gamage, 2020).

Survey analysis data further suggested that online lab discussion sessions helped them to be able to understand the objective of the experiment, to be able to identify required labware, and also to identify the procedure to perform an experiment. In their opinion, completing the online labs have helped them to perform better in lecture quizzes and exams as well.

Nevertheless, student's do not get enough opportunities to collaborate with other student's/ group members as a part of the remote lab like in the case of a physical lab. They further claim that they have very much limited opportunities for peer learning through remote lab. Especially in the engineering disciplines, students appear to be very uncomfortable to go and work in the industry with remote lab experience as a part of their degree.

However, students much appreciated that they were able to acquire knowledge while staying at home without wasting their time. But we have to understand the fact that laboratory training not only provides practical knowledge but also contribute to developing many other important aspects of education such as creativity, critical thinking and problem-solving skills of the student(Daud \& Razali, 2016). Hence, it appears that there's a considerable gap in bringing remote laboratories to meet up to the standards of physical laboratories if universities plan to depend solely on remote laboratories.

Even though, the virtual laboratory is considered as an emergeing trend to offer a safe environment enabling convenient platform to deliver practical training, still virtual laboratories could discourage direct interactions and transferable skills such as team-work and communication skills and collaborative activities that can be appreciated in traditional laboratory training (Gravier et al., 2012). Physical laboratory set up provides additional benefits to the students that are lacking in remote laboratory setting. To name a few, the ability to interact with peers to discuss ideas/approaches and to solve problems together greatly help for the development of social skills and professional work environment (Grout, 2017). Hence, future research and potentials lie in a wide range of areas in developing remote laboratory approaches to meet the essential requiremnts.

\section{CONCLUSION}

The critical importance of laboratory education and practical training in many educational fields has been emphasized in many research articles. Laboratory practical knowledge with hands-on experience is essential to understand theoretical concepts better. Remote laboratory approaches are considered to be the best option available considering the pandemic situation. However, the development of remote laboratory tools and technologies to apply in various engineering, technology and many more fields is highly encouraged enabling the capability to perform experiments in real-time.

Based on the literature search, we were able to identify the various approaches followed and attempted to get the best out of remote learning. New avenues have also been proposed for the further development of remote laboratory in terms of improving the extent of interaction among students.

Being these online laboratory practices are widely emerging in STEM education at the university level, in a case-based study conducted by Chan \& Fok, (2009) suggests that further 
research needs to be carried out to identify how the online practice can be exploited to enhance the overall teaching and learning process.

Literature highlights that the instructors' contribution is also undoubtedly important in online laboratory delivery (Simon et al., 2020). Furthermore, a study conducted by Flowers (2011), suggests that future work needs to be conducted to identify whether the interaction with the instructor and the student collaboration effect on the student performance as well.

When considering the use of the remote laboratory in undergraduate level education, the user accesses the experiment from a remote location and has a virtual presence in the laboratory including the required instruments and the setup. This concept is feasible since experiments were well practiced and expected results were already known to program the particular experiment. These type of virtual labs consisting of 3-D simulations (e.g Praxilabs) provide a real-time experience feeling similar to the student working inside the lab and getting observations and results as the experiment proceeds (Srivastawa et al., 2020).

Most of the time remote laboratory practices fail to provide adequate resources when it comes to real research work including high-end research activities and innovations conducted by graduate students, post-docs and many other research scientists. For instance, one of the many fields include research studies on pathogenesis-related diagnostic and therapeutic innovations considering the COVID-19 pandemic itself where it requires biologically active live samples in real-time (Srivastawa et al., 2020)

Moreover, research studies continue to incorporate digital and smart software and apps to provide better services in terms of assistive technological improvements and userfriendliness. Such improvements include in the area of speech recognition and screen reading software (Dragon speech recognition, Windows narrator), smart-pens that could record everything that is heard, said and written (Liverscibe Smartpen) (Grout., 2020).

In the physical mode of delivery, visual presence helps to drive the attention, accountability, and engagement of the learners. Whereas, in a remote laboratory setting an individual requires to be self-disciplined and self-motivated and to be able to work alone. Therefore, considerable practice would require especially for the fresh undergraduates to adapt and familiarize themselves with the virtual environment. Further-more developments in technology will address to introduce laboratory interfaces that could be customized based on the experimental requirements as well as by means of receiving experimental results and data etc.

Despite the attempts in achieving the learning outcomes and basic laboratory skills, further research needs to be conducted to identify how effectively the teamwork skills, are gained by the students through online laboratory practices as well.

A hands-on experience in certain subject disciplines cannot be solely delivered through online laboratory activities, further research needs to be conducted to identify whether any type of novel techniques can be applied in those laboratory sessions, and how universities compensate for the quality of education through online laboratory activities.

\section{ACKNOWLEDGEMENTS}

The authors would like to thank the students who participated in the survey for their feedback and support given in getting better insight into the review paper. 


\section{REFERENCES}

Akçayır, M., Akçayır, G., Pektaş, H. M., \& Ocak, M. A. (2016). Augmented reality in science laboratories: The effects of augmented reality on university students' laboratory skills and attitudes toward science laboratories. Computers in Human Behavior, 57, 334-342.

American Association of Physics Teachers. (2014). AAPT recommendations for the undergraduate physics laboratory curriculum. Report prepared by a subcommittee of the AAPT committee on laboratories.

Andújar, J. M., Mejias, A., \& Marquez, M. A. (2011). Augmented reality for the improvement of remote laboratories: An augmented remote laboratory. IEEE Transactions on Education, 54(3), 492-500. https://doi.org/10.1109/TE.2010.2085047

Aziz, E. S. S., Esche, S. K., \& Chassapis, C. (2009). Content-rich interactive online laboratory systems. Computer Applications in Engineering Education, 17(1), 61-79. https://doi.org/10.1002/cae.20210

Borrero, A. M., Sánchez, M. A. M., Márquez, J. M. A., \& Herrera, M. R. S. (2013). A complete solution for developing remote labs. IFAC proceedings volumes (IFAC-PapersOnline), 10(PART 1), 96-101. https://doi.org/10.3182/20130828-3-UK-2039.00057

Chan, C., \& Fok, W. (2009). Evaluating learning experiences in virtual laboratory training through student perceptions: a case study in electrical and electronic engineering at the University of Hong Kong. Engineering Education, 4(2), 70-75. https://doi.org/10.11120/ened.2009.04020070

Chen, X., Song, G., \& Zhang, Y. (2010). Virtual and remote laboratory development: A review. Proceedings of the 12th international conference on engineering, science, construction, and operations in challenging environments - earth and space 2010, 41096(March), 3843-3852. https://doi.org/10.1061/41096(366)368

Cherner, Y., Cima, M., Barone, P., Van Dyke, B., \& Lotring, A. (2020). Interactive and adaptable cloud-based virtual equipment and laboratories for 21st century science and engineering education. EPiC Ser Educ Sci, 3, 47-53.

Crawford, J., Butler-henderson, K., Rudolph, J., Malkawi, B., Glowatz, M., Magni, P. A., \& Sophia Lam. (2020). COVID-19: 20 countries' higher education intra-period digital pedagogy responses. Journal of Applied Learning \& Teaching, 3(1). https://doi.org/10.37074/jalt.2020.3.1.7

Cuendet, S., Bonnard, Q., Do-Lenh, S., \& Dillenbourg, P. (2013). Designing augmented reality for the classroom. Computers and Education, 68, 557-569. https://doi.org/10.1016/j.compedu.2013.02.015

Dan-Ologe, I. A., \& Shittu, A. O. (2012). Improving the standard of teaching and learning of practicals in our secondary schools: Emphasis on biology and chemistry practicals. Journal of Qualitative Education, 8(1), 1-5.

Darrah, M., Humbert, R., Finstein, J., Simon, M., \& Hopkins, J. (2014). Are virtual labs as effective as hands-on labs for undergraduate physics? A comparative study at two major universities. Journal of Science Education and Technology, 23(6), 803-814. https://doi.org/10.1007/s10956-014-9513-9

Daud, M. H., \& Razali, Z. B. (2016). UniMAP e-Lab for electrical engineering technology: Future online laboratory classes. In MATEC Web of Conferences (Vol. 78, p. 01008). EDP Sciences.

Dhawan, S. (2020). Online Learning: A Panacea in the time of COVID-19 crisis. Journal of Educational Technology Systems, 49(1), 5-22. https://doi.org/10.1177/0047239520934018

Flowers, L. O. (2011). Investigating the effectiveness of virtual laboratories in an undergraduate biology course. Journal of Human Resources \& Adult Learning, 7(December), 110-116.

Gamage, T. D. M. . K. A. A. (2020). Novel coronavirus (COVID-2019) pandemic: Common challenges and response from higher education providers. Journal of Applied Learning \& Teaching, 3(2), 4-13. https://doi.org/10.37074/jalt.2020.3.2.20

Gibbs, G., \& Habeshaw, T. (2011). Preparing to teach an introduction to effective teaching in higher education.

Gravier, C., Fayolle, J., Lardon, J., \& O’Connor, M. J. (2012). Adaptive system for collaborative online laboratories. IEEE Intelligent Systems, 27(4), 11-17. https://doi.org/10.1109/MIS.2011.1

Grout, I. (2017). Remote laboratories as a means to widen participation in STEM education. Education Sciences, 7(4). https://doi.org/10.3390/educsci7040085

Hafni, R. N., Herman, T., Nurlaelah, E., \& Mustikasari, L. (2020). The importance of science, technology, engineering, and mathematics (STEM) education to enhance students' critical thinking skill in facing the industry 4.0. Journal of Physics: Conference Series, 1521(4), 0-7. https://doi.org/10.1088/17426596/1521/4/042040 
Kapilan, N., Vidhya, P., \& Gao, X. Z. (2021). Virtual laboratory: A Boon to the mechanical engineering education during Covid-19 pandemic. Higher Education for the Future, 8(1), 31-46. https://doi.org/10.1177/2347631120970757

Kemp, N. (2020). University students' perceived effort and learning in face-to-face and online classes. Journal of Applied Learning \& Teaching, 3(Special Issue). https://doi.org/10.37074/jalt.2020.3.s1.14

Khan, T., Johnston, K., \& Ophoff, J. (2019). The impact of an augmented reality application on learning motivation of students. Advances in Human-Computer Interaction, 2019. https://doi.org/10.1155/2019/7208494

Loike, J. D., \& Stoltz-Loike, M. (2020). How to rethink science lab classes. Retrieved November 26, 2020. https://www.insidehighered.com/advice/2020/04/08/five-objectives-online-science-labs-lend-themselvesvirtual-teaching-opinion

Mejías Borrero, A., \& Andújar Márquez, J. M. (2012). A pilot study of the effectiveness of augmented reality to enhance the use of remote labs in electrical engineering education. Journal of Science Education and Technology, 21(5), 540-557. https://doi.org/10.1007/s10956-011-9345-9

Odeh, S., Shanab, S. A., Anabtawi, M., \& Hodrob, R. (2012). Remote augmented reality engineering labs. IEEE Global engineering education conference, EDUCON. https://doi.org/10.1109/EDUCON.2012.6201162

Potkonjak, V., Gardner, M., Callaghan, V., Mattila, P., Guetl, C., Petrović, V. M., \& Jovanović, K. (2016). Virtual laboratories for education in science, technology, and engineering: A review. Computers \& Education, 95, 309327.

Rowe, R. J., Koban, L., Davidoff, A. J., \& Thompson, K. H. (2018). Efficacy of online laboratory science courses. Journal of Formative Design in Learning, 2(1), 56-67. https://doi.org/10.1007/s41686-017-0014-0

Sarumi, O. A. (2020). Virtual Reality as a tool for learning: The past, present and the prospect. Journal of Applied Learning \& Teaching, 3(2), 51-58. https://doi.org/10.37074/jalt.2020.3.2.10

Simon, L. E., Genova, L. E., Kloepper, M. L. O., \& Kloepper, K. D. (2020). Learning postdisruption: Lessons from students in a fully online nonmajors laboratory course. Journal of Chemical Education, 97(9), 2430-2438. https://doi.org/10.1021/acs.jchemed.0c00778

Thees, M., Kapp, S., Strzys, M. P., Beil, F., Lukowicz, P., \& Kuhn, J. (2020). Effects of augmented reality on learning and cognitive load in university physics laboratory courses. Computers in Human Behavior, 108, 106316. https://doi.org/10.1016/j.chb.2020.106316

Thibaut, D., \& Schroeder, K. T. (2020). A case-based learning approach to online biochemistry labs during COVID19. Biochemistry and Molecular Biology Education, 48(5), 484-485. https://doi.org/10.1002/bmb.21408

Uhomoibhi, J., Ubwa, F., \& Ibhuiyan, I. (2014). Virtual and remote laboratory implementation in engineering education and research: Sharing, use and evaluation of online experiment resources. Proceedings of 2014 international conference on Interactive Collaborative Learning, ICL 2014, December, 1095-1099. https://doi.org/10.1109/ICL.2014.7017918

Wang, L. Q., \& Ren, J. (2020). Strategies, practice and lessons learned from remote teaching of the general chemistry laboratory course at brown university. Journal of Chemical Education, 97(9), 3002-3006.

https://doi.org/10.1021/acs.jchemed.0c00746 